\title{
Educational Service Quality in Zanjan University of Medical Sciences from Students' Point of View
}

\author{
Ali Mohammadi ${ }^{1, *}$ \& Jamshid Mohammadi ${ }^{2}$ \\ ${ }^{1}$ Department of Public Health, Faculty of Health, Zanjan University of Medical Sciences, Iran \\ ${ }^{2}$ Department of Parasitology, Faculty of Medicine, Zanjan University of Medical Sciences, Iran \\ *Corresponding author: Department of Public Health, Faculty of Health, Parvin Etesami St, Zanjan, Iran. Tel: \\ 98-24-3377-3128. E-mail: ali@zums.ac.ir
}

Received: June 12, 2014

doi:10.5430/wje.v4n5p86
Accepted: September 29, $2014 \quad$ Online Published: October 17, 2014

URL: http://dx.doi.org/10.5430/wje.v4n5p86

\begin{abstract}
This study aims at evaluating perceived service quality in Zanjan University of Medical Sciences (ZUMS). This study was cross-sectional and authors surveyed educational services at ZUMS. Through stratified random sampling, 384 students were selected and an adapted SERVQUAL instrument was used for data collection. Data analysis was performed by using SPSS 11.5. The results indicated that there were the negative mean score of quality gap in all

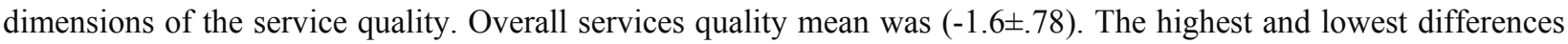
of mean scores between students' expectations and perceptions were in the responsiveness and $(-1.83 \pm 1.01)$ and reliability $((-1.33 \pm .79)$ dimensions respectively. Paired t-test showed the significant statistical differences between students' expectations and perceptions $(\rho<0.001)$ in all dimensions of the service quality. Thus, improvement actions are felt in all domains of the educational service quality; Students rated the responsiveness as the most important dimension of service quality in ZUMS.
\end{abstract}

Keywords: higher education; service quality; students' expectations; students' perception; Zanjan

\section{Introduction}

Universities play a key role in economic, social and cultural development. Likewise, in Iran, they have the responsibility of training professional manpower demanded by industry, agriculture and service (Bazargan, 2001). In addition, service quality is emphasized due to social requirements of quality evaluation in education (Zafiropoulos and Varna, 2008). Moreover, service quality creates a competitive advantage for organizations (Stodnick, and Rogers, 2008). Regarding the above reasons, the issue of service quality assessment is given serious consideration in universities (Cuthbert, 1996).

There was very limited access to higher education in Iran until 1990. However, it has grown rapidly during two last decades (Bavarian, 2001; Bazargan, 2002). Along with quantity increase in Iranian universities, quality improvement in education seems necessary. Promotion of service quality increases customer satisfaction in organizations (Stodnick \& Rogers, 2008). On the other hand, organization resources are scarce and limited, and to improve quality of services, they must be aware of their costumers' needs and expectations, and accordingly identify the quality attributes embraced by the costumers (Chua, 2004). Thus, available resources of organization should be allocated in terms of significance of service quality dimensions from costumers' point of view.

\section{Literature Review}

According to Berry (1995) an organization's success is positively influenced by the service quality. Identifying and measuring costumers' expectations and perception are an essential step for the improvement of organization's service provision.

Quality service is defined as the costumers' perceptions of service performance in order to meet or exceed their expectations of what the service organization should do. Thus, the service quality is to fulfill costumer expectations 
(Pariseau and McDaniel, 1996). Service quality was measured by employing one-dimensional scale by researchers (Parasuraman, Zeithaml, and Berry, 1988). However, Hjorth (1984) believed that measurement of a multi-component subject like quality through one-dimensional scales is inappropriate.

Parasuraman et al. (1988) developed a multi- dimensional instrument - SERVQUAL- to measure quality of perceived service. Service quality is the difference between costumers' expectations and perceptions of the actual performance of a specific organization based on the SERVQUAL.

It has 22 items and measures customers' expectations and perceptions of service quality in the following domains:

(1) Tangibles: that is related to physical facilities of organization (equipment and personnel appearance).

(2) Reliability: an organization can provide the promised service dependably and accurately.

(3) Responsiveness: how employees in organization is willing to help costumers and provide prompt service

(4) Assurance is related to employees' knowledge and modest behavior and their ability to inspire trust and confidence in customers

(5) Empathy: how much organization is attending to costumers' individual needs (Schneider, and White, 2004).

SERVQUAL identifies the gaps of service quality between rated expectations and performance (perceptions) and it shows the areas that require improvement as priorities.

Measuring service quality in a higher educational context is not a new topic, and a number of studies have been accomplished in this field following the study of (Parasuraman, Zeithaml, and Berry, 1988).

Soutar and McNeil (1996) used SERVQUAL to evaluate performance in higher education. The authors evaluated both the teaching dimension of a higher education organization and the aspects of total environment of service from the students' point of view. LaBay and Comm (2003) also studied a sample of undergraduate students and surveyed students' perceptions and expectations of their teachers. Kong and Muthusamy (2011) used service gap scores to classify quality attributes in higher education in Malaysia.

In a study by Pariseau and McDaniel(1996) on measuring service quality in faculty of business in USA by using SERVQUAL instrument on samples of students and faculty, both groups rated assurance as the most important dimension in higher education services, and students rated responsiveness, empathy, reliability and tangibles as the second to fifth determinant of quality respectively.

In the study of Aghamolaei and Zare (2008) on educational services quality in Hormozgan University of medical sciences, the results indicated that quality gaps were negative in all the SERVQUAL dimensions. The highest and the lowest mean scores of quality gap were in responsiveness and reliability dimensions respectively.

In the study of Kebriaei and Roudbari(2005) on the educational services quality in Zahedan university of medical sciences, the highest and the lowest means of scores were in the responsiveness and tangibles dimensions respectively.

Universities in Iran have changed toward qualitative expansion now; thus, research in quality of educational services seems necessary. However, studies performed in Iran have only assessed the quality of teaching as the present situation from students' point of view, and quality gap has been neglected (Kebriaei and Roudbari, 2005). Regarding the importance of identification of students' expectations and perceptions to improve the quality of educational services and reduce the gap between the present and real situation, this study was conducted with the aim of evaluating perceived quality of service (the gap between perception and expectation levels of service quality) in Zanjan University of Medical Sciences.

\section{Methods and Materials}

\subsection{Study Design}

This study was a cross-sectional research and the data consisted of second semester to last-year medical sciences students' responses to closed-ended questions about their expectations and perceptions of educational services quality.

\subsection{Participants}

Students of ZUMS in 2011 were the study population. ZUMS has four faculties including medicine; nursing and midwifery; health and paramedics, and pharmacology. 384 students were selected through stratified random 
sampling. Twenty percent of the students in each faculty were selected randomly. Samples included 84, 140, 42 and 118 students from faculties of medicine, paramedics and health, pharmacology and nursing respectively. Out of 384 students, 370 participants agreed to fill out the questionnaire, while 50 questionnaires were not analyzed due to incomplete or missing data. Regarding the above cases, response rate was $86 \%$

\subsection{Instrument}

To measure quality of educational service, a modified version of SERVQUAL questionnaire developed by Parasuraman, Zeithaml, and Berry (1988) was used.

This questionnaire was specifically developed to measure quality in the service organizations (Schneider, and White, 2004). A number of modifications were made to adjust this instrument to a higher education institution. The modified SERVQUAL was made up of twenty-nine items enquiring the expected and perceived level of educational services in five following dimensions: Reliability (seven items), responsiveness (five items), assurance (five items), empathy (seven items) and tangibles (five items).

Content validity and reliability of Persian version of this questionnaire in a study by (Kebriaei and Roudbari, 2005) in Iran was approved. Coefficients of Cronbach Alpha related to services quality dimensions were reliability 0.82, responsiveness 0.83 , assurance 0.82 , empathy 0.86 and tangibles 0.79 .

\subsection{Procedure}

To rate quality of the educational services in the university, the students selected one option in each item (varying from very good to very poor). To rate importance of the quality of educational service, the students selected one option in each item (varying from very important to the least important). Five - point Likert scale was used, where (5) was very important/very good and (1) represented the least important/very poor.

To facilitate answers, an instruction page was prepared. The students were informed about the scale as follows: $(5=$ very important/very good, $4=$ important /good, $3=$ fairly important /average, $2=$ low importance/ poor and $1=$ the least important/very poor). Column headings in the questionnaire for expectations section were labeled as "How important is this service to you?", and for perceptions section "How is this service provided in this university?"

To calculate score of each domain, the scores of the statements of each domain were summed and mean score was calculated. Services quality (SQ) is the difference between expectations (E) and perceptions (P), (P-E= SQ). Negative SQ indicates that the university has not met the students' expectations and vice versa.

\subsection{Statistical Analysis}

Descriptive statistics such as mean, standard deviation (SD), paired t-test, and one - way ANOVA were utilized to analysis the results and the study data were analyzed by SPSS11.5. Mean scores of perceptions and expectations were utilized to judge about students' expectations and perceptions of educational service quality. The gap score was calculated using SERVQUAL equation:

Service quality $(\mathrm{Q})=$ perception $(\mathrm{p})$-expectation $(\mathrm{E})$.

Medical Ethics Committee of ZUMS approved the present study.

\section{Results}

\subsection{Demographic Data of Participants}

The mean age of participants was $21.32 \pm 2.27$ years. One hundred and forty (43.7\%) of participants were male and $180(56.3 \%)$ were female. Female students of ZUMS exceed their male peers. Ninety six $(30 \%)$ were in super diploma level, 119 (37.2\%) in Bachelor of Science (BS) level, and 105 (32.8\%) in medicine and pharmacology level. Seventy $(21.9 \%)$ were in medical school, $35(10.9 \%)$ were in pharmacology school, $98(30.60 \%)$ were in faculty of midwifery and nursing and 117 (36.6\%) were in faculty of health and paramedics.

\subsection{Overall Mean of Services Quality}

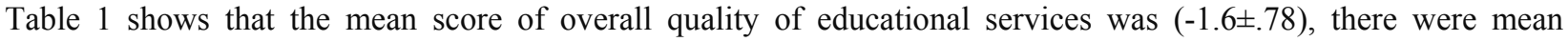
differences between students' expectations and perceptions in all dimensions. The highest and lowest differences of mean scores between students' expectations and perceptions were in the responsiveness dimension $(-1.83 \pm 1.01)$ and reliability dimension $(-1.33 \pm .79)$ respectively. Paired t-test showed a statistical significant difference between students' expectations and perceptions $(\rho<0.001)$ in all dimensions of the service quality. In fact, students' expectations have not been met in any of educational service quality dimensions. 
Table 1. Mean Scores of Expectations, Perceptions, SERVQUAL (quality gap) of Education Service Quality Dimensions and Paired t-test $(\mathrm{N}=320)$

\begin{tabular}{lllllc}
\hline Education service quality items & Perception & Expectation & Gap & Value of t & P value \\
\hline Tangibility & $2.69 \pm .75$ & $4.37 \pm .58$ & $-1.68 \pm .9$ & -28.02 & $<0.001$ \\
Reliability & $3.16 \pm .66$ & $4.49 \pm .56$ & $-1.33 \pm .79$ & -23.56 & $<0.001$ \\
Responsiveness & $2.56 \pm .8$ & $4.4 \pm .64$ & $-1.83 \pm 1.01$ & -27.31 & $<0.001$ \\
Assurance & $2.79 \pm .83$ & $4.45 \pm .57$ & $-1.65 \pm .98$ & -25.37 & $<0.001$ \\
Empathy & $3 \pm .8$ & $4.49 \pm .58$ & $-1.48 \pm .95$ & -23.24 & $<0.001$ \\
Total SERVQUAL & $2.84 \pm .62$ & $4.44 \pm .54$ & $-1.6 \pm .78$ & -29.51 & $<0.001$ \\
\hline
\end{tabular}

\subsection{Perceived Service Quality}

Table 2 shows the findings related to expectations, perceptions and quality gaps in the items of educational services.

\subsubsection{Perceptions}

As table 2 shows, two of the highest perceptions (P 7 and P10) are in the reliability dimension and three of the highest perceptions (P27, P 28 and P29) are in the empathy dimension. Two of the lowest perceptions (P 2 and P3) are in the tangible dimension, two of the lowest perceptions (P15 and P17) are in the responsiveness dimension and one of the lowest perceptions is item P19 in the assurance dimension.

\subsubsection{Expectations}

Table 2 shows that mean scores of all expectation items were greater than four, thus students rated all of the service quality items important.

\subsubsection{Gap of Service Quality (P-E)}

The third column of table 2 shows gap scores of the service quality. The largest difference between perceptions and expectations is item SQ12 in the reliability dimension; one of the largest differences between perceptions and expectations is item SQ2 in the tangible dimension; two of the largest differences between perceptions and expectations (SQ15 and SQ17) are in the responsiveness dimension and one of the largest differences between perceptions and expectations, SQ19, is in the assurance dimension.

All items have a negative score, indicating that the students ' expectations of the educational service are not met in ZUMS. Paired t-test showed that the differences between students ' expectations and perceptions were statistically significant at level $(\rho<.01)$.

Table 2. Mean Score of the Students' Expectations, Perceptions and Quality Gaps in Items of Educational Service

\begin{tabular}{lccccc}
\hline Items & P* & $\mathbf{E}^{* *}$ & Service & \multicolumn{2}{l}{ Paired T-Test } \\
\cline { 5 - 7 } & & & gap & $\mathbf{t}$ & $\mathbf{p}$ \\
\hline Tangibles & & & & & \\
\hline 1.Neat ant professional appearance of academic & 3.14 & 4.37 & -1.23 & -15.05 & $<0.001$ \\
members and staff & & & & & \\
2. Comfortable physical facilities and visual appealing & 2.56 & 4.53 & -1.97 & -24.41 & $<0.001$ \\
3. Existence of guide signal with visual attraction & 2.18 & 4.13 & -1.95 & -24.14 & $<0.001$ \\
4. Up to date educational equipment and material & 2.86 & 4.51 & -1.65 & -19.77 & $<0.001$ \\
5. Visual appealing of teaching tools & 2.7 & 4.32 & -1.62 & -20.16 & $<0.001$ \\
\hline Reliability & & & & & \\
\hline 6. Presenting educational content regularly and relevant & 2.97 & 4.51 & -1.54 & -19.63 & $<0.001$ \\
7. Provide feedback on students' progress & 3.28 & 4.41 & -1.13 & -13.27 & $<0.001$ \\
8. Presenting lesson content understandably & 2.96 & 4.58 & -1.61 & -20.62 & $<0.001$ \\
9. Gaining higher scores if students attempt more & 3.20 & 4.42 & -1.22 & -14.66 & $<0.001$ \\
\hline
\end{tabular}




\begin{tabular}{|c|c|c|c|c|c|}
\hline $\begin{array}{l}\text { 10. Recording students' educational documents } \\
\text { without mistake }\end{array}$ & 3.47 & 4.50 & -1.03 & -12.38 & $<0.001$ \\
\hline $\begin{array}{l}\text { 11. Easy accessibility to academic references in } \\
\text { university }\end{array}$ & 3.15 & 4.52 & -1.37 & -17.19 & $<0.001$ \\
\hline $\begin{array}{l}\text { 12. Fulfilling responsibilities by lecturers and } \\
\text { staff in the promised time }\end{array}$ & 3.06 & 4.51 & -2.44 & -18.4 & $<0.001$ \\
\hline \multicolumn{6}{|l|}{ Responsiveness } \\
\hline 13. when students need supervisors, they are accessible & 2.68 & 4.40 & -1.72 & -20.51 & $<0.001$ \\
\hline $\begin{array}{l}\text { 14. Students can express their views about the } \\
\text { curriculum to administrators }\end{array}$ & 2.58 & 4.46 & -1.88 & -21.13 & $<0.001$ \\
\hline $\begin{array}{l}\text { 15. Students' suggestions and views are considered in } \\
\text { curriculum }\end{array}$ & 2.29 & 4.38 & -2.08 & -24.34 & $<0.001$ \\
\hline $\begin{array}{l}\text { 16. Appropriate references are introduced to students for } \\
\text { reading }\end{array}$ & 3.23 & 4.40 & -1.17 & -14.21 & $<0.001$ \\
\hline $\begin{array}{l}\text { 17. Definitive hours are declared that students can refer } \\
\text { to talk about educational problems }\end{array}$ & 2.05 & 4.31 & -2.26 & -24.77 & $<0.001$ \\
\hline \multicolumn{6}{|l|}{ Assurance } \\
\hline 18. Free discussion and interaction about lessons in class & 2.78 & 4.34 & -1.56 & -18.89 & $<0.001$ \\
\hline 19. Preparing students for their professional job & 2.46 & 4.48 & -2.02 & -22.55 & $<0.001$ \\
\hline $\begin{array}{l}\text { 20. Lecturers are accessible at free time to answer } \\
\text { students' questions }\end{array}$ & 2.72 & 4.36 & -1.64 & -19.05 & $<0.001$ \\
\hline $\begin{array}{l}\text { 21. Adequate references are available to increase } \\
\text { students' professional knowledge }\end{array}$ & 2.92 & 4.49 & -1.57 & -19.28 & $<0.001$ \\
\hline 22. Lecturers have adequate professional knowledge & 3.06 & 4.60 & -1.54 & -17.18 & $<0.001$ \\
\hline \multicolumn{6}{|l|}{ Empathy } \\
\hline 23. Assigning suitable and relevant homework & 2.83 & 4.34 & -1.51 & -17.77 & $<0.001$ \\
\hline $\begin{array}{l}\text { 24. Flexibility of lecturers when exposing to specific } \\
\text { conditions of each student }\end{array}$ & 2.59 & 4.40 & -1.81 & -19.29 & $<0.001$ \\
\hline 25. Suitable hours for lesson classes & 2.6 & 4.45 & -1.85 & -21.31 & $<0.001$ \\
\hline $\begin{array}{l}\text { 26. Convenient and silent place are available in school } \\
\text { for reading }\end{array}$ & 2.86 & 4.52 & -1.67 & -18.85 & $<0.001$ \\
\hline 27. Behavior of school staff are respectful with students & 3.24 & 4.56 & -1.32 & -15.26 & $<0.001$ \\
\hline 28. Behavior of lecturers are respectful with students & 3.58 & 4.59 & -1.01 & -12.27 & $<0.001$ \\
\hline $\begin{array}{l}\text { 29.Respectful treatment of faculty management with } \\
\text { students }\end{array}$ & 3.32 & 4.55 & -1.23 & -13.97 & $<0.001$ \\
\hline
\end{tabular}

*Perception **Expectation

One - way ANOVA test showed the difference between mean score of the students' perceptions on the basis of educational level, except tangibles and responsiveness dimensions was not significant, whereas differences in mean scores of expectations and gaps among them were statistically significant (table 3 ). 
Table 3. Comparison of the Mean Scores of Service Gaps, Expectations and Perceptions on the Basis of Students' Educational Levels

\begin{tabular}{lllll}
\hline $\begin{array}{l}\text { Service } \\
\text { Dimension }\end{array}$ & educational level & perception & expectation & service gap \\
\hline Tangibles & General medicine & 2.92 & 4.53 & -1.62 \\
& Bachelor of Science & 2.55 & 4.51 & -1.96 \\
& Super diploma & 2.6 & 4.02 & -1.41 \\
& One way ANOVA & $\mathbf{p}^{* *}=.001$ & $\mathrm{p}<0.01$ & $\mathrm{p}<0.01$ \\
\hline Reliability & General medicine & 3.13 & 4.61 & -1.48 \\
& Bachelor of Science & 3.1 & 4.65 & -1.55 \\
& Super diploma & 3.26 & 4.16 & -.9 \\
& One way ANOVA & $\mathrm{p}=0.21$ & $\mathrm{p}<0.01$ & $\mathrm{p}<0.01$ \\
\hline Responsiveness & General medicine & 2.40 & 4.53 & -2.14 \\
& Bachelor of Science & 2.65 & 4.57 & -1.92 \\
& Super diploma & 2.65 & 4.04 & -1.39 \\
& One way ANOVA & $\mathrm{p}=0.03$ & $\mathrm{p}<0.01$ & $\mathrm{p}<0.01$ \\
\hline Assurance & General medicine & 2.75 & 4.58 & -1.83 \\
& Bachelor of Science & 2.77 & 4.59 & -1.82 \\
& Super diploma & 2.85 & 4.11 & -1.26 \\
& One way ANOVA & $\mathrm{p}=0.67$ & $\mathrm{p}<0.01$ & $\mathrm{p}<0.01$ \\
\hline Empathy & General medicine & 3 & 4.64 & -1.64 \\
& Bachelor of Science & 2.99 & 4.66 & -1.67 \\
& Super diploma & 3 & 4.12 & -1.11 \\
& One way ANOVA & $\mathrm{p}=0.99$ & $\mathrm{p}<0.01$ & $\mathrm{p}<0.01$ \\
\hline Total service & General medicine & 2.84 & 4.58 & -1.74 \\
quality & Bachelor of Science & 2.81 & 4.60 & -1.78 \\
& Super diploma & 2.87 & 4.09 & -1.21 \\
& One way ANOVA & $\mathrm{p}=0.78$ & $\mathrm{p}<0.01$ & $\mathrm{p}<0.01$ \\
\hline
\end{tabular}

$* *$ P. value

\section{Discussion and Conclusion}

\subsection{Discussion}

This study aimed at evaluating students' opinion about the educational services quality by a modified SERVQUAL questionnaire in ZUMS. The findings of this study showed that the students' expectations have not been met in any of the dimensions of the quality of educational services. This confirms the results of the Pariseau and McDaniel (1996), Ham and Hayduk (2003), Oliveira and Ferreira (2009)' Barnes (2005), and Aghamolaei and Zare (2008). Negative quality gap scores mean that the students' expectations have not been met in any of service quality dimensions, and there is dissatisfaction among students. For students' satisfaction, university should take improvement actions in all dimensions of educational services.

The highest and the lowest mean score of quality gap were in the responsiveness and reliability dimensions respectively in the present study. This finding corresponds with the results of Smith, Smith, and Clarke's study (2007). Pariseau and McDaniel's study (1996) showed that business faculty at both schools did not meet students' expectations.

In Ham and Hayduk's study (2003) on higher education of the Netherlands about service quality, expectation mean scores were slightly higher than perception mean score for responsiveness, assurance, empathy, and tangibility.

In Oliveira and Ferreira's study (2009) on using the SERVQUAL questionnaire in higher education in Brazil, responsiveness dimension had the highest negative mean score among the five dimensions. The difference between expectations and perceptions (P-E) for all items in this dimension was negative. The security (assurance) dimension was important for the students who were beginning undergraduate studies.

In the study by Barnes (2005) on analyzing service quality in post-graduate students in China, all the items of service quality had a negative score; implying that students' expectations have not been met. 
In the study by Aghamolaei and Zare (2008) on quality gap of educational services, mean of quality gaps scores were negative in all dimensions of educational service. The highest and the lowest mean scores were in the responsiveness and reliability domains respectively.

The negative mean score of quality gap in dimensions of the service quality and their items implies necessity of some improvements in educational services quality. The highest mean score of negative gap was related to the responsiveness domain. This domain indicates the faculty's tendency and readiness to assist students, declaring hours to discuss educational problems of student, and provide prompt services. The highest mean score of negative gap in the responsiveness domain and its statements indicates that the administrators do not allocate enough time to solve students educational problems; the university lacks an open management system in the education affairs ; the administrators do not utilize students' points of view and suggestions in class planning and curriculum; lecturers do not introduce the suitable references to students for covering lesson topics; there are not regular programs for students counseling. Faculty members are not easily accessible outside the class due to workload and do not allocate enough time to answer students' questions.

The negative mean score of quality gap in other dimensions implies that students' expectations have not been well met. With regard to students viewpoints and the negative mean score of quality gap in all dimensions of the service quality, the following hints could be used to improve service quality: a) Empowering manpower (staff and faculty members) to solve student educational problems by holding educational workshops in the contexts such as "how to increase communicative skills", "developing educational staff professional knowledge", and "improving communication between lecturers and students". The administrators should also schedule class hours of lecturers so that they can allocate adequate time for educational consultation. b) The administrators should consider students ideas and educational problems when they want to prepare the curriculum so that students can easily express their viewpoints to the administrator. c) Providing adequate scientific references (books, journals, educational aid equipment and ...) to improve knowledge and prepare lesson plans on the basis of future jobs needs. d) Finally, applying the new teaching methods (student involvement in preparing class programs, active participation of students in teaching, problem-based learning, discussion).

\subsection{Limitations}

The research findings are limited by several factors. This study examined the responses of students in a single university. The results might be inapplicable to other universities.

Universities in Iran have different equipment, facilities and staff, and this study may not be the representative sample of the whole country. Thus, the findings of this study may be useful for other universities; however, it cannot be generalized to all universities.

\subsection{Conclusion}

The findings indicated that there were the negative mean scores of quality gap in all service quality dimensions. Thus, taking improvement actions seems necessary in all domains of the educational service quality. Students rated the responsiveness as the most important dimension in the higher education service setting in Iran.

Therefore, the findings will be useful for educational institutions in prioritizing actions and allocation of limited resources to achieve positive outcomes in the satisfaction levels of students (Arambewela, and Hall, 2006). Thus, the service quality dimensions regarding their negative scores can be placed into three priority groups for provision of resources and executive actions for improvement of educational service quality. The first, second, and third priorities are related to responsiveness; tangibles and assurance; and the reliability and empathy domains respectively. If the university take the priorities into consideration, students' satisfaction will be achieved (Lamei, 2000).

\section{Acknowledgment}

The authors thank the Research Deputy in the ZUMS for assistance and providing financial support for this study.

\section{References}

Aghamolaei, T., \& Zare, S. (2008). Quality gap of educational services in viewpoints of students in Hormozgan University of Medical Sciences. BMC Medical Education, 8(1), 34. http://dx.doi.org/10.1186/1472-6920-8-34

Arambewela, R., \& Hall, J. A. (2006). Comparative Analysis of International Education Satisfaction Using SERVQUAL. Journal of Services Research, 6(3), 141-163. 
Barnes, B. R. (2005). Analyzing Service Quality: The Case of Post-Graduate Chinese Students. Department of Marketing, Leeds University Business School, University of Leeds, UK, 2(2), 1-31.

Bazargan A. (2001). Educational evaluation: concepts, pattern and operational processes. Tehran: SAMT. (In Persian).

Bazargan, A. (2002). Measuring Access to Higher education and Higher education quality: A case study from Iran. Prospects, 32(3). http://dx.doi.org/10.1023/A:1022189614413

Berry, L.L. (1995). Relationship marketing of services-growing interest, emerging perspectives. Journal of the Academy of Marketing sciences, 26, 767-786.

Chua, C. (2004). Perceptions of Quality in higher education. Proceedings of the Australian universities quality forum. AUQA occasional publication. Retrieved from http://www.auqa.edu.au/auqf/2004/program/papers/Chua.pdf

Cuthbert, P. (1996). Managing service quality in Higher Education: is SERVQUAL the answer? Part 1. Managing Service Quality, 6(2), 11-16. http://dx.doi.org/10.1108/09604529610109701

Ham, L., \& Hayduk, S. (2003).Gaining Competitive Advantages in Higher Education: Analyzing the Gap between Expectations and Perceptions of Service Quality. International Journal of Value-Based Management, 16, 223-242. http://dx.doi.org/10.1023/A:1025882025665

Hjorth, A.C. (1984). The Concept of Quality and the Efficiency of Markets for Client Products. Journal of Client Research, February, 708-7 18.

Kebriaei, A., \& Roudbari, M. (2005). Quality gap in educational services at Zahedan university of medical sciences: students viewpoints about current and optimal condition. Iranian Journal of Medical Education, 5(1), 53-60.

Kong, S. M., \& Muthusamy, K. (2011). Using service gaps to classify quality attributes. The TQM Journal, 23(2), 145 -163. http://dx.doi.org/10.1108/17542731111110212

LaBay, D.G., \& Comm., C.L. (2003). A case study using gap analysis to assess distance learning versus traditional course delivery. The International Journal of Education Management, 17(6, 7), 312-317.

Lamei, A. (2000). Total Quality management in health care. Ministry of Health and Education of Iran. Quality Improvement Unit.

Oliveira, O. J., \& Ferreira, E. C. (2009). Adaptation and application of the SERVQUAL scale in higher education. 20th Annual Conference.

Parasuraman, A., Zeithaml, V. A., \& Berry, L.L. (1988). SERVQUAL: A Multiple-Item Scale for Measuring Client Perceptions of Service Quality. Journal of Retailing, 64(1), 12-40.

Pariseau, S. E., \& McDaniel, J.R. (1996). Service quality in schools of business. IJQRM, 14(3), 204- 218.

Schneider, B., \& White, S.S. (2004). Service quality: research approach. London, UK: SAGE Publications.

Smith, G., Smith, A., \& Clarke, A. (2007). Evaluating service quality in universities: a service department perspective. Quality Assurance in Education, 15(3), 334-351. http://dx.doi.org/10.1108/09684880710773200

Soutar, G., \& McNeil, M. (1996). Measuring service quality in a tertiary institution. Journal of Educational Administration, 34(1), 72-82. http://dx.doi.org/10.1108/09578239610107174

Stodnick, M., \& Rogers, P. (2008). Using SERVQUAL to Measure the Quality of the Classroom Experience. Decision Sciences Journal of Innovative Education, 6(1), 115-134. http://dx.doi.org/10.1111/j.1540-4609.2007.00162.x

Zafiropoulos, C., \& Vrana, V. (2008). Service Quality Assessment in a Greek Higher Education Institute. Journal of Business Economics and Management, 9(1), 33-45. http://dx.doi.org/10.3846/1611-1699.2008.9.33-45 